\title{
Biofilm-Producing Candida Species Causing Oropharyngeal Candidiasis in HIV Patients Attending Sukraraj Tropical and Infectious Diseases Hospital in Kathmandu, Nepal
}

This article was published in the following Dove Press journal: HIVIAIDS - Research and Palliative Care

\author{
Keshav Lamichhane (iD ${ }^{1, *}$ \\ Nabaraj Adhikari $\mathbb{D}^{1, *}$ \\ Anup Bastola $\mathbb{D}^{2}$ \\ Lina Devkota $\mathbb{D}^{2}$ \\ Parmananda Bhandari ${ }^{2}$ \\ Binod Dhungel' \\ Upendra Thapa Shrestha (1D \\ Bipin Adhikari (1D ${ }^{3}$ \\ Megha Raj Banjara (D) \\ Komal Raj Rijal (D) \\ Prakash Ghimire (D) \\ 'Central Department of Microbiology, \\ Tribhuvan University, Kathmandu, Nepal; \\ ${ }^{2}$ Sukraraj Tropical and Infectious Disease \\ Hospital, Teku, Kathmandu, Nepal; \\ ${ }^{3}$ Centre for Tropical Medicine and Global \\ Health, Nuffield Department of Medicine, \\ University of Oxford, Oxford, UK
}

*These authors contributed equally to this work
Introduction: Oropharyngeal candidiasis are the commonest fungal infections among HIVpositive patients. The main objective of this study was to explore biofilm-producing Candida species causing oropharyngeal infections among HIV patients attending Sukraraj Tropical and Infectious Diseases Hospital (STIDH) in Kathmandu, Nepal.

Methods: Oropharyngeal swabs were collected from the HIV-positive patients between July and December 2019. A total of 174 oropharyngeal swabs were cultured on Sabouraud Dextrose Agar (SDA). All samples were inoculated on SDA slants supplemented with chloramphenicol and underwent incubation at $37^{\circ} \mathrm{C}$ for $24-48$ hours. Any visible growth reported was processed for the identification of the species. Candida species were differentiated based on the growth and colour of the isolates on CHROM agar candida. Biofilm production in Candida species was determined by the microtiter plate method (MPM). Antifungal susceptibility testing was performed using the disc diffusion method.

Results: Among 174 oropharyngeal samples, $23.6 \%(n=41 / 174)$ of them had oropharyngeal infections and $36.6 \%$ of the oropharyngeal infections (15/41) had CD4 T-lymphocytes count below 200 cells $/ \mathrm{mm}^{3}$ who were also active tobacco users $(\mathrm{p}<0.05)$. Among Candidial growth, 61\% (25/41) were Candida albicans and 39\% (16/41) were non-albicans. Of 41 Candida spp., 65\% (27/41) were biofilm producers. An equal proportion of Candida albicans (4 isolates) and non-albicans (4 isolates) were strong biofilm producers. C. albicans isolates were sensitive towards clotrimazole $(96 \% ; 24 / 25)$ and fluconazole $(92 \% ; 23 / 25)$, whereas sensitivity towards ketoconazole was only $48 \%$ (12/25). Non-albicans Candida was highly sensitive to amphotericin-B $(62.5 \% ; 10 / 16)$ followed by clotrimazole $(56.2 \% ; 9 / 16)$. The biofilm-producing Candida isolates showed the highest resistivity $(51.9 \%$; $14 / 27)$ to ketoconazole and lowest $(22.2 \% ; 6 / 27)$ to clotrimazole.

Conclusion: Oropharyngeal candidiasis is a common opportunistic infection among HIVinfected individuals. The majority of cases of oropharyngeal candidiasis are caused by biofilm producers Candida albicans and non-albicans Candida. Biofilm producers Candida were more resistant towards commonly used antifungal drugs.

Keywords: oral candidiasis, HIV, Candida albicans, biofilm, antifungal susceptibility test

\section{Background}

Globally, estimated 37.9 million people were found living with Human Immunodeficiency virus (HIV) infections in 2018. ${ }^{1}$ Estimated 3.5 million people were found living with HIV in South-East Asia and bears the second highest burden 
after Sub-Saharan Africa. ${ }^{2}$ Among 11 South-East Asian Countries, Nepal has an estimated $0.14 \%$ prevalence rate of HIV with $0.03 \%$ incidence per 1,000 population. A total of 35,062 HIV cases and 3,617 HIV deaths were reported in Nepal since the first case of HIV detected in 1988. Estimated 873 new HIV cases were scattered in different parts of Nepal in $2018 .^{3}$

HIV virus infection reduces the number and functionality of CD4 helper T-lymphocytes that direct and coordinate acquired immunity against most pathogens. ${ }^{4}$ The decrease in immunity leads to various opportunistic infections (OIs) in HIV-infected persons. ${ }^{5}$ Candida is one of the saprophytic microorganisms that are mostly transient flora in immunologically active individuals. ${ }^{6,7}$ Various factors such as immune suppression, malnutrition, dental malocclusion, poor oral hygiene are found to be contributing factors for oropharyngeal candidiasis. ${ }^{8}$ Candida are beneficial flora found in mucus membranes of ears, eyes, gastrointestinal tract, mouth, nose, reproductive organs, sinuses, skin, stool and vagina. An imbalance in the normal flora can lead to the development of Candidiasis or Thrush. Candida causing the oral candidiasis are the same Candida species which are normally found in the oral cavity. ${ }^{9}$

One of the commonest oral manifestations among HIVpositive patients is oral candidiasis ${ }^{10-12}$ that infects more or less $90 \%$ of patients. ${ }^{13}$ Candida albicans represents the most common causative agent of oral candidiasis; nonetheless, over the recent years, other species of Candida have been emerging with varying pathogenicity and antifungal susceptibility. ${ }^{14,15}$ Although the incidences of opportunistic infection have reduced around the globe by highly active antiretroviral therapy (ART), the burden of OIs in low- and middle-income countries are proportionately higher due to poor quality of health services and the coverage. $^{16}$

Low CD4 count $(<200)$ is a hallmark for the opportunistic infections in Acquired Immune Deficiency Syndrome (AIDS). ${ }^{17}$ The lower the CD4 count, the higher is the risk of opportunistic fungal infections. A study from Kathmandu valley reported $50 \%$ of the patients with the fungal infections had a CD4 count below 200 cells $/ \mu \mathrm{L} .{ }^{18}$ Development of oral candidiasis is predicated on various factors that include age, sex, smoking, alcohol consumption, xerostomia, antibiotic usage $\geq 7$ days, CD4 counts $<104.5 \mathrm{cell} / \mu \mathrm{L}$ and the stage of HIV infection. ${ }^{19}$ Tobacco use is considered as a predisposing factor for oral candidiasis $^{20,21}$ that can lead to symptomatic infection in immune-compromised patients. ${ }^{22}$ The rate of oral candidal infection was found higher in smokers compared to nonsmokers. ${ }^{21}$

The commonly used antifungal drugs show significant variation in the susceptibility towards the Candida species. ${ }^{23}$ The drug resistance has significantly increased over the last decades due to the growing use of antifungal agents over the counter and without susceptibility testing. ${ }^{24}$ The increase in resistant Candida species may be due to prolonged or constant treatment with antifungal drug azoles. An epidemiologic change pattern of Candida species could altogether affect the utility of fluconazole as empiric treatment for oropharyngeal candidiasis patients with HIV positive. ${ }^{25}$ Globally, several studies have reported the emergence of drug-resistant Candida species. The change in drug susceptibility pattern of Candida species and the introduction of newer antifungal agents has made the in vitro susceptibility testing of antifungal agents more relevant. ${ }^{26,27}$ Thus, the isolation, identification, characterization and susceptibility testing of Candida species in clinical specimens have become increasingly important for the management of fungal infections.

In Nepal, studies exploring the prevalence of oral candidiasis in HIV-infected patients are limited. Few studies have reported the prevalence of bacterial and fungal opportunistic infections in HIV-infected patients from STIDH, Kathmandu, ${ }^{18}$ Tribhuvan University Teaching Hospital, Kathmandu, ${ }^{28}$ and Manipal Teaching Hospital, Pokhara. ${ }^{29}$ However, none of these studies included antimicrobial susceptibility of fungal opportunistic pathogens. The availability of antimicrobials over the counter coupled with high empiric treatment adds to the burgeoning antimicrobial resistance in Nepal, ${ }^{30,31}$ narrowing the therapeutic options to treat fungal OIs among HIV patients.

The current study represents HIV patients attending STIDH, a national referral center for the treatment of HIV/AIDS patients based in Kathmandu. The main objective of this study was to determine the prevalence of Candida spp. causing oropharyngeal candidiasis and their susceptibility to commonly prescribed antifungal drugs. The variability in the prevalence of different Candida spp. and the increasing number of clinical isolates resistant to current antifungal therapies highlight the need for antifungal susceptibility testing to monitor the antifungal resistance of these microorganisms. Thus, this study is expected to guide the management and therapeutic choice to treat fungal OIs among HIV patients attending STIDH. 


\section{Materials and Methods}

A total of 174 HIV/AIDS patients who attended STIDH between July and December 2019 and clinically confirmed oropharyngeal candidiasis (based on the observation of erythematous patches or white, scrapable pseudomembranous lesions on buccal cavity) were included in the study. All cases were confirmed HIV/AIDS with clinical and laboratory diagnosis based on the national guidelines for the treatment of HIV/AIDS. ${ }^{32} \mathrm{~A}$ written informed consent was obtained from each participant. Data were collected using a questionnaire through face-to-face interviews. Socio-demographic, clinical and behavioral data of patients included age, sex, HIV diagnosed date, CD4 counts, ART status, ART initiation date, and tobacco use (whether the participants have tobacco chewing or cigarette smoking habit on at least after HIV diagnosed) were collected and were entered first in Microsoft Excel, and were later analyzed using SPSS version 24.0, Armonk, NY: IBM Corp.

\section{Inclusion and Exclusion Criteria}

A patient was enrolled in this study if he/she was HIV positive and attended STIDH; was clinically diagnosed to have oropharyngeal candidiasis \{Types included pseudomembranous: $(\mathrm{P})$, erythematous: $(\mathrm{E})$, angular cheilitis: (AC), and the combination of any one of these $\}$; and provided written informed consent regardless of their ART status. People living with HIV/AIDS who were below 18 years of age were excluded from the study.

\section{Specimen Collection, Sample Size and Processing}

A total of 174 oropharyngeal swabs were collected from HIV patients attending STIDH, Teku, Kathmandu from July to December 2019. Oropharyngeal swabs were collected using spatula and sterile cotton swab. The spatula was used to hold down the tongue to avoid picking normal flora from the tongue. The sterile cotton swab sticks were used to gently swab the oropharyngeal surface without contaminating the tongue and were quickly streaked on the surface of SDA slants supplemented with chloramphenicol. The agar slants were transported to the Microbiology Laboratory of STIDH. The plates were incubated at $37^{\circ} \mathrm{C}$ aerobically for 24-48 hours. ${ }^{33,34}$ The colonies that were pasty and creamy were sub-cultured on SDA to get pure cultures for further confirmation.

\section{Identification of Candida Species}

Fungal isolates were identified macroscopically and microscopically based on the colonial morphology of the isolates on the culture media. Mucoid yeast-like growth was processed using Gram's staining and germ tube test and urease test. All the isolates were observed for Gram-positive budding yeast cells. ${ }^{35}$ Suspected Candida based on the Grampositive budding yeast were tested for germ tube formation. ${ }^{4}$ Candida albicans and non-albicans Candida species were differentiated based on the type of the growth and colour of isolates on CHROM agar Candida (HiMedia, Mumbai, India) and sugar fermentation and sugar assimilation test. The Candida species were identified as described in the manufacturer's instruction: Candida albicans (Green), C. tropicalis (Blue), C. glabrata (Pink), C. krusei (Dry pink). Then, $C$. dubliniensis and $C$. albicans both are germ tube positive and C. albicans was further confirmed based on their ability to grow at $45^{\circ} \mathrm{C} .{ }^{35,36}$

\section{Biofilm Production by Microtiter Plate Method (MTP)}

A colony of each isolate of Candida species was inoculated into tubes containing $2 \mathrm{~mL}$ of brain heart infusion (BHI) broth and incubated at $37^{\circ} \mathrm{C}$ for 24 hours. After 24 hours, broth culture was diluted at a ratio of 1:20 using fresh BHI broth. Two hundred microliter of the diluted solution was placed into microtiter plates and incubated at $37^{\circ} \mathrm{C}$ for 24 hours. The microtiter plates were subsequently drained and rinsed with distilled water (DW) for 2-3 times, and were inverted to blot. Each well was then filled with $200 \mu \mathrm{L}$ of $1 \%$ crystal violet and was incubated for 15 minutes. After incubation, the microtiter plates were washed again three times with DW. About $200 \mu \mathrm{L}$ of ethanol: acetone mixture (4:1) was added to each well and were read at $450 \mathrm{~nm}$ using an ELISA reader, and Optical Density (OD) was recorded for each well. Sterile BHI broth was used as the negative control. The strains were classified as 'non-producers', 'moderate producers' and "strong producers" based on the ODs of Candida biofilms. The cut-off value was determined by arithmetically averaging the OD of the wells containing sterile BHI broth and adding a standard deviation of +2 . Samples with an OD higher than the cut-off value were considered positive, whereas those with the lower optical density than the cut-off value were considered as negative. ${ }^{37}$ 


\section{Antifungal Susceptibility Test}

Antifungal susceptibility testing was performed and interpreted for all the isolates of Candida using the disc diffusion method based on the Clinical and Laboratory Standards Institute (CLSI) M44 document guidelines. ${ }^{38}$ The inoculum was prepared by suspending five colonies of growth in $5 \mathrm{~mL}$ of sterile saline and turbidity was compared with 0.5 McFarland Standard. A cotton swab was dipped into the inoculum suspension and evenly streaked onto Mueller-Hinton agar supplemented by $2 \%$ glucose and $5 \mu \mathrm{g} / \mathrm{mL}$ methylene blue. ${ }^{24}$ C. albicans ATCC 90028 and C. tropicalis ATCC 750 were used as controls for identification and antifungal susceptibility test. Antifungal discs containing fluconazole $(25 \mu \mathrm{g})$, ketoconazole $(15 \mu \mathrm{g})$, clotrimazole $(10 \mu \mathrm{g})$, and amphotericin-B $(10 \mu \mathrm{g})$ were placed on the inoculated MHA Plate and incubated. The zone of inhibition around the disc was measured after incubating the media at $37^{\circ} \mathrm{C}$ for 24 hours. $^{33}$

\section{Statistical Analysis}

Data were entered and analyzed using IBM SPSS Statistics for Windows, Version 24.0, Armonk, NY: IBM Corp. Descriptive and inferential statistics were analyzed. Association of oral candidiasis with gender, CD4+ count, ART status and tobacco use was tested using a Chi-squared test. A p-value $<0.05$ was considered statistically significant.

\section{Results}

Among 174 oropharyngeal swabs samples collected from HIV-positive patients attending STIDH, 23.6\% $(\mathrm{n}=41 / 174)$ of patients had oropharyngeal infections and $76.4 \%$ $(n=133 / 174)$ had no oropharyngeal infections (Figure 1).

\section{Demographic and Clinical Characteristics of HIV-Positive Patients}

Of 41 HIV patients with candidal oropharyngeal infections, 53.7\% (22/41) were male and 46.3\% (19/41) were female. HIV patients of age group (41-50) years had the highest candida infection $(34.2 \% ; 14 / 41)$ followed by age group (31-40) years $(31.7 \% ; 13 / 41)$. Out of 41 candida oropharyngeal infections, $93.7 \%(38 / 41)$ were receiving antiretroviral treatment and 36.6\% (15/41) had CD4 T-lymphocytes count below 200 cell $/ \mathrm{mm}^{3} .24 .4 \%(10 / 41)$ of HIV patients with oropharyngeal candidiasis had CD4 T-lymphocytes above 500 cell $/ \mathrm{mm}^{3}$. Of 41 candidiasis patients, $36.6 \%(15 / 41)$ had a habit of consuming tobacco.
Growth pattern of Candida species from oropharyngeal swab of HIV positive patients $(n=174)$

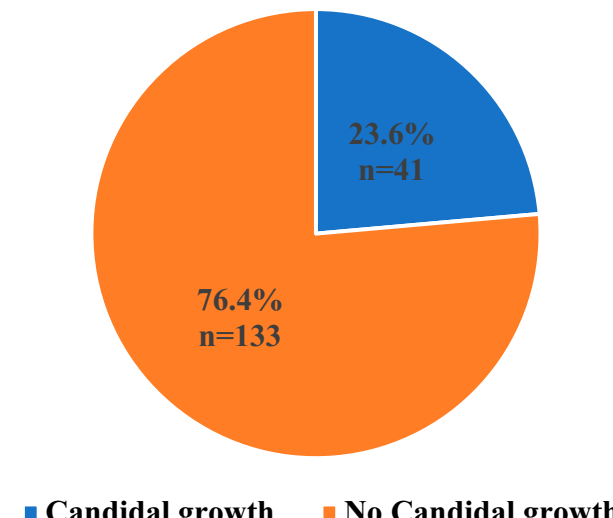

Figure I Growth pattern of Candida spp. from oropharyngeal swabs of HIVpositive patients.

There was a significant association between oropharyngeal candidiasis and tobacco consumption $(\mathrm{p}=0.01)$ (Table 1).

\section{Biofilm Production in Candida Species}

Among candidal growth, 61\% (25/41) were Candida albicans and 39\% (16/41) were non-albicans Candida spp.: $(14.6 \% ; 6 / 41)$ were $C$. parapsilosis followed by $C$. tropicalis (9.8\%;3/41) (Figure 2). Of 41 Candida spp., 65\% (27/41) were biofilm producers, among which 16 were Candida albicans and 11 were non-albicans Candida spp. Among 27 biofilm producers Candida spp., 8 were strong biofilm producers and 19 were moderate biofilm producers. The equal proportion of Candida albicans and non-albicans Candida were strong biofilm producers and there was no significant correlation between Candida species and biofilm formation $(\mathrm{r}=-0.93)$. Type of species, gender, antiretroviral therapy, CD4 T-lymphocytes and tobacco consumption were not associated with biofilm production whereas age factor was significantly related to biofilm production in Candida spp $(\mathrm{p}=0.008)$ (Table 2).

\section{Antifungal Susceptibility Pattern of Candida albicans and Non-Albicans Candida from Oropharyngeal Swab Sample of HIV Patients}

C. albicans isolates were highly sensitive towards clotrimazole $(96 \% ; 24 / 25)$ and fluconazole $(92 \% ; 23 / 25)$, whereas sensitivity towards ketoconazole was only $48 \%$ (12/25). The highest sensitivity of non-albicans Candida was in antifungal drug amphotericin-B $(62.5 \% ; 10 / 16)$ followed by clotrimazole $(56.2 \% ; 9 / 16)$. C. albicans was highly resistant to antifungal 
Table I Sociodemographic and Clinical Characteristics of HIV Positive Samples $(\mathrm{N}=174)$

\begin{tabular}{|c|c|c|c|c|c|}
\hline \multirow[t]{3}{*}{ Characteristics } & \multicolumn{4}{|c|}{ Candida Colonization } & \multirow[t]{3}{*}{ p-value } \\
\hline & \multicolumn{2}{|l|}{ Positive } & \multicolumn{2}{|l|}{ Negative } & \\
\hline & Number & $\%$ & Number & $\%$ & \\
\hline \multicolumn{6}{|l|}{ Gender } \\
\hline Male & 22 & 53.7 & 70 & 52.6 & 0.908 \\
\hline Female & 19 & 46.3 & 63 & 47.4 & \\
\hline \multicolumn{6}{|l|}{ Age years } \\
\hline $18-30$ & 11 & 26.8 & 49 & 36.8 & 0.21 \\
\hline $31-40$ & 13 & 31.7 & 48 & 36.1 & \\
\hline $4 \mid-50$ & 14 & 34.2 & 29 & 21.8 & \\
\hline $51-60$ & 3 & 7.3 & 5 & 3.8 & \\
\hline$>60$ & 0 & & 2 & 1.5 & \\
\hline \multicolumn{6}{|l|}{$\begin{array}{l}\text { Anti-retroviral } \\
\text { treatment }\end{array}$} \\
\hline Yes & 38 & 93.7 & 125 & 94 & 0.76 \\
\hline No & 3 & 7.3 & 8 & 6 & \\
\hline \multicolumn{6}{|c|}{$\begin{array}{l}\text { CD4 T-lymphocytes } \\
\text { cell } / \mathrm{mm}^{3}\end{array}$} \\
\hline$<200$ & 15 & 36.6 & 19 & 14.3 & $0.05^{*}$ \\
\hline $200-499$ & 16 & 37 & 56 & 42.1 & \\
\hline$>500$ & 10 & 24.4 & 58 & 43.6 & \\
\hline \multicolumn{6}{|l|}{$\begin{array}{l}\text { Habit of taking } \\
\text { tobacco }\end{array}$} \\
\hline Yes & 15 & 36.6 & 24 & 18 & $0.01 *$ \\
\hline No & 26 & 63.4 & 109 & 82 & \\
\hline
\end{tabular}

Note: *Significant.

drug ketoconazole $(52 \% ; 13 / 25)$ whereas non-albicans candida was resistant to fluconazole $(68.7 \% ; 11 / 16)$ (Table 3).

\section{Antifungal Susceptibility Pattern of Biofilm Producers and Non-Producers Candida}

The biofilm-producing Candida isolates showed the highest resistivity $(51.9 \%$; 14/27) towards ketoconazole whereas lowest resistance $(22.2 \%$; 6/27) was found in clotrimazole. Non-biofilm-producing Candida isolates showed the highest resistivity $(42.9 \%$; $6 / 14)$ towards ketoconazole and lowest resistance $(14.3 \% ; 2 / 14)$ was found in clotrimazole. In tested four antifungal agents, biofilm producers showed higher resistance compared to non-biofilm producers (Figure 3).

\section{Discussion}

\section{Overall Findings}

In this study, one fourth of the HIV-positive patients had oropharyngeal Candidiasis. Findings in this study are consistent with a similar study reported from the same hospital
Distribution Of Candida species in HIV patients with oropharyngeal candidiasis $(\mathrm{N}=41)$

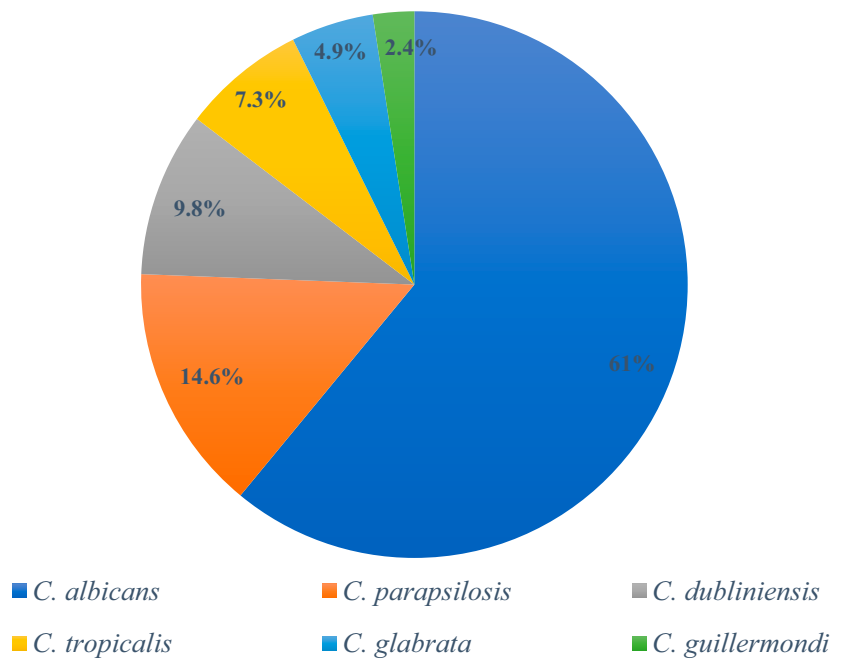

Figure 2 Distribution of different Candia species in HIV patients.

(STIDH). ${ }^{18}$ However, the prevalence of oral candidiasis is found to be low in comparison to previous studies from Nepal, ${ }^{28,39}$ India, ${ }^{40-42}$ Brazil, $^{43,44}$ and Iran. ${ }^{45}$ The lower prevalence of oral candidiasis in this study than the other previous studies from Nepal can be attributed to patients' strict adherence to their antiretroviral regimen. Regular checkup of HIV-infected individuals in various ART centers, government strategies to minimize opportunistic infections and rising health-seeking behavior may have contributed to a decrease in the oral candidiasis rate.

\section{Sociodemographic Factors, Clinical Factors and Candida Colonization}

In our study, nearly equal proportion of male and female HIV-positive participants had oropharyngeal candidiasis and was not significantly associated with gender. The findings of our study are similar to other studies reported from Tribhuvan University Teaching Hospital, Maharajgunj, Kathmandu, ${ }^{24}$ AIDS referral center in Londrina, Brazil ${ }^{46}$ and Goiás, Brazil. ${ }^{47}$

In our study, oropharyngeal candidiasis was reported more in HIV-positive patients who were under ART and oral candidiasis and ART status was not statistically significant. A similar pattern of findings was reported in a study conducted in Brazil, ${ }^{47}$ and Ghana. ${ }^{48}$ Highly active antiretroviral therapy has been associated with a drastic decrease in the rates of HIV related opportunistic infections. Antiretroviral therapy can exert a direct effect on Candida virulence by inhibiting the fungal secretory 
Table 2 Relation of Various Demographic Factors and Biofilm Production in Candida spp ( $\mathrm{n}=4 \mathrm{I})$

\begin{tabular}{|c|c|c|c|c|c|c|c|c|c|}
\hline \multirow{3}{*}{$\begin{array}{l}\text { Characters } \\
\text { Type of Candida }\end{array}$} & \multicolumn{9}{|c|}{ Biofilm Production } \\
\hline & \multicolumn{2}{|l|}{ Strong } & \multicolumn{2}{|l|}{ Moderate } & \multicolumn{2}{|c|}{ Non-Producers } & \multicolumn{2}{|l|}{ Total } & \multirow[t]{2}{*}{ p-value } \\
\hline & Number & $\%$ & Number & $\%$ & Number & $\%$ & Number & $\%$ & \\
\hline Candida albicans & 4 & 50 & 12 & 63.2 & 9 & 64.3 & 25 & 61 & $p=0.77$ \\
\hline Non albicans Candida & 4 & 50 & 7 & 36.8 & 5 & 35.7 & 16 & 39 & $r=-0.93$ \\
\hline \multicolumn{10}{|l|}{ Gender } \\
\hline Male & 6 & $75 \%$ & 8 & 42.1 & 8 & 57.1 & 22 & 53.7 & 0.27 \\
\hline Female & 2 & 25 & 11 & 57.9 & 6 & 42.9 & 19 & 46.3 & \\
\hline \multicolumn{10}{|l|}{ Age in years } \\
\hline $18-30$ & 0 & & 4 & 21.1 & 7 & 50 & 11 & 26.8 & 0.008 \\
\hline $31-40$ & 7 & 87.5 & 3 & 15.8 & 3 & 21.4 & 13 & 31.7 & \\
\hline $4 I-50$ & I & 12.5 & 9 & 47.4 & 4 & 28.6 & 14 & 34.1 & \\
\hline $5 I-60$ & 0 & 0 & 3 & 15.8 & 0 & 0 & 3 & 7.3 & \\
\hline \multicolumn{10}{|l|}{ Antiretroviral therapy } \\
\hline Yes & 8 & 100 & 18 & 94.7 & 12 & 85.7 & 38 & 92.7 & 0.41 \\
\hline No & 0 & & 1 & 5.3 & 2 & 14.3 & 3 & 7.3 & \\
\hline \multicolumn{10}{|l|}{ CD4 T-lymphocytes } \\
\hline$<200$ & 2 & 25 & 6 & 31.6 & 7 & 50 & 15 & 36.6 & 0.75 \\
\hline $200-499$ & 4 & 50 & 8 & 42.1 & 4 & 28.6 & 16 & 39 & \\
\hline$>500$ & 2 & 25 & 5 & 26.3 & 3 & 21.4 & 10 & 24.4 & \\
\hline \multicolumn{10}{|l|}{ Habit of taking tobacco } \\
\hline Yes & 5 & 62.5 & 4 & 21.1 & 6 & 42.9 & 15 & 36.6 & 0.1 \\
\hline No & 3 & 37.5 & 15 & 78.9 & 8 & 57.1 & 26 & 63.4 & \\
\hline
\end{tabular}

Table 3 Antifungal Susceptibility Pattern of Candida Species

\begin{tabular}{|c|c|c|c|c|}
\hline \multirow[t]{3}{*}{ Antifungal Drugs } & \multicolumn{2}{|c|}{ Candida albicans $(\mathrm{n}=25)$} & \multicolumn{2}{|c|}{ Non-albicans Candida $(n=16)$} \\
\hline & Resistance & Sensitive & Resistance & Sensitive \\
\hline & Number (\%) & Number (\%) & Number (\%) & Number (\%) \\
\hline Amphotericin B $(10 \mu g)$ & $4(16.0)$ & $21(84.0)$ & $6(37.5)$ & $10(62.5)$ \\
\hline Clotrimazole $(10 \mu \mathrm{g})$ & $\mathrm{I}(4.0)$ & $24(96.0)$ & $7(43.8)$ & $9(56.2)$ \\
\hline Fluconazole $(25 \mu \mathrm{g})$ & $2(8.0)$ & $23(92.0)$ & II (68.7) & $5(3 \mid .3)$ \\
\hline Ketoconazole ( $15 \mu \mathrm{g})$ & $13(52.0)$ & $12(48.0)$ & 7 (43.8) & $9(56.2)$ \\
\hline
\end{tabular}

aspartyl proteinases (SAPs). ${ }^{47}$ This might be due to genetic characteristics of isolates and low level of SAPs production which reduces the potential target for the antiretroviral agents. ${ }^{49}$

A low count of CD4+ cells $/ \mu \mathrm{L}(<200$ cells/ul) was an important contributor to increase the probability of oral Candida colonization. In our study, one third of HIVpositive patients had $\mathrm{CD} 4+$ cells below 200 cells $/ \mu \mathrm{L}$ and there was a significant association between oral candidiasis and low CD4+ count. The findings are consistent with the past studies conducted in STIDH, Kathmandu, ${ }^{18}$ New Delhi,
India, ${ }^{50}$ Italy, ${ }^{51}$ Awka, Nigeria, ${ }^{52}$ and Nigeria. ${ }^{53}$ However, the findings of our study were in contrast with other studies reported from India ${ }^{40}$ and Brazil. ${ }^{46,47,54}$ The precise defense mechanisms that limit the Candida proliferation are still unclear. Other factors such as blood group secretor status, salivary low rates, antimicrobial constituents of saliva, lysozyme and lactoferrin release, presence of normal bacteria flora and local mucosal immune system could have an impact on the development of oral infection by Candida. ${ }^{55}$

In our study, we found tobacco-chewing habit as one of the predisposing factors for colonization of Candida spp in 


\section{Antifungal resistance pattern in bioflim producers and Non producers}

Candida spp

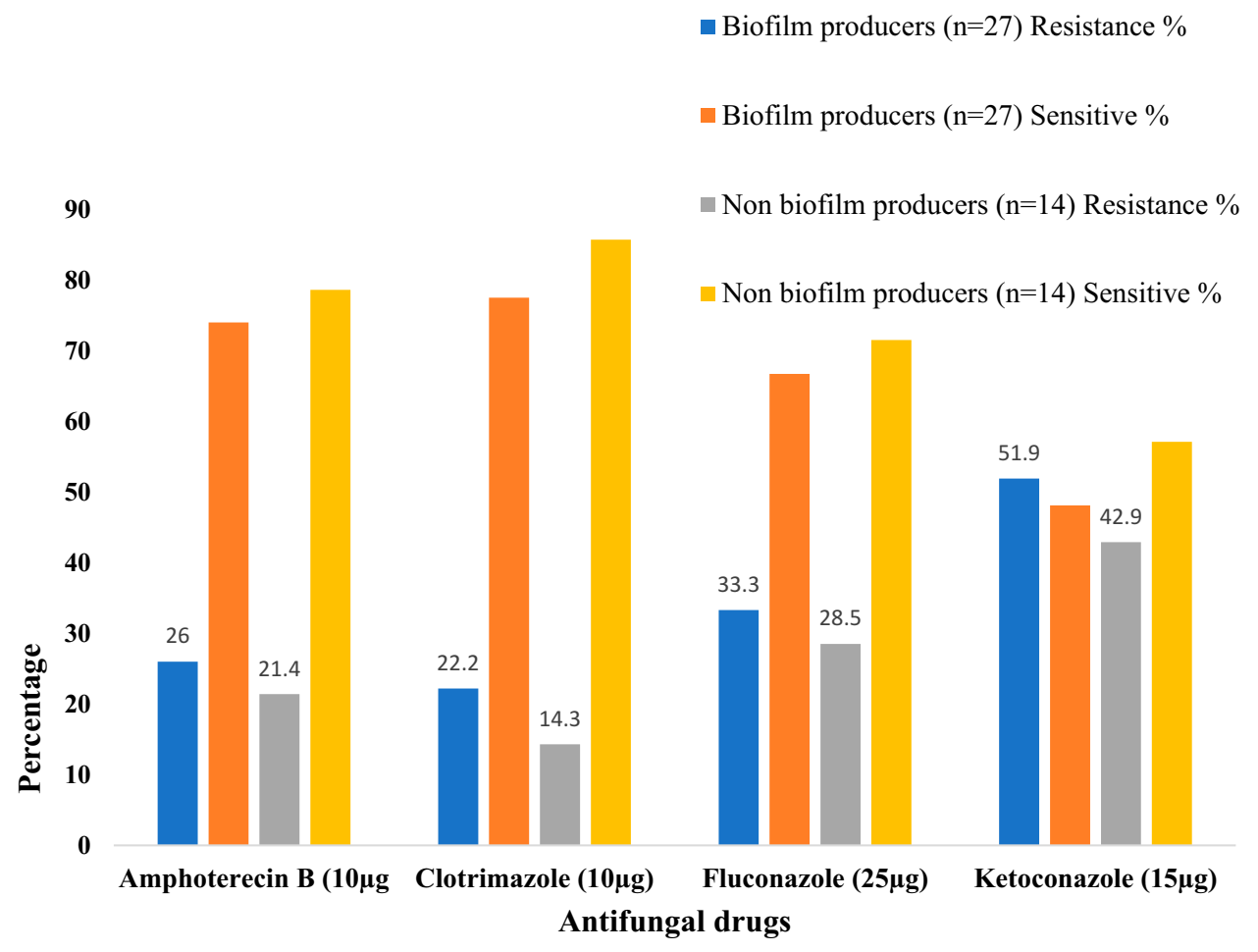

Figure 3 Antifungal resistance pattern in biofilm producers and non-producer Candida species.

oropharyngeal tract. The findings of our study were in line with other studies reported from New Delhi, India ${ }^{21}$ and Himanchal, India; ${ }^{56}$ however, it was inconsistent with the report from Jordan. ${ }^{57}$ Tobacco-chewing habit increases the level of nitrosamines in the oral cavity, which can change the normal microflora, increasing the number of pathogenic bacteria and fungi. It also decreases salivary $\mathrm{pH}$ and increases phosphorus-ion concentration resulting in a significant acidic environment and leading to dryness of the mouth, which favors the accumulation of Candida spp. in the oral cavity. ${ }^{58}$

\section{Types of Candida Species, Biofilm Producers}

In this study, Candida albicans was the major species isolated from HIV-positive patients with oropharyngeal candidiasis. The findings of our study are consistent with the previous studies reported from Nepal, ${ }^{18,24,59}$ and India. $^{40,60}$ The prevalence of oral candidiasis in HIVinfected individuals varies with the environment, although Candida albicans remains generally the most implicated. ${ }^{61}$ While Candida albicans is the most prevalent species involved in both mucocutaneous and disseminated infections, the incidence of candidiasis due to non-albicans Candida is increasing. Several factors such as severe immunosuppression or illness, co-morbidities, use of broad-spectrum antibiotics, and empirical use of antimycotic drugs are reported to be associated with an increase in non-albicans candida. ${ }^{62}$

In this study, two third isolates of Candida albicans were biofilm producers. Biofilm production is slightly high in nonalbicans Candida. Our findings were correlated with other similar studies reported from Pokhara, ${ }^{59}$ and India. ${ }^{37}$ Each Candida species exhibits differences in terms of biofilm formation at the level of their morphology, characteristics of the extracellular matrix (ECM), and the ability to confer antifungal resistance. ${ }^{63}$ These biofilms are notoriously difficult to eliminate and serve as a source of recalcitrant infections, their study is highly useful for assessing public health. ${ }^{64}$

\section{Antifungal Susceptibility Pattern}

In this study, Candida species were found to be more susceptible to clotrimazole followed by amphotericin B and fluconazole whereas $50 \%$ isolates of Candida were resistant to 
ketoconazole. The findings are similar to the study conducted at Tribhuvan University, Teaching Hospital, Kathmandu. ${ }^{24}$ A study conducted in China reported amphotericin B as the most efficient antifungal drug; ${ }^{65}$ however, we found clotrimazole as the most effective drug against Candida followed by amphotericin B. This might be due to widespread use of amphotericin-B for the treatment of fungal infections without antifungal susceptibility test in Nepal. Over the counter availability of antimicrobials including amphotericin B and high empiric treatment (without a confirmatory diagnosis) in Nepal may have been adding to the drug pressure. ${ }^{30,31}$ In our study, a higher rate of fluconazole resistance was found in non-albicans Candida than Candida albicans. The reason could be due to high inherent resistance to azoles among nonalbicans Candida. ${ }^{66}$ In this study, biofilm producers showed higher resistance than non-biofilm producers towards every antifungal agent. Biofilm production is related to a high level of antifungal resistance of the associated microorganisms. Moreover, the ability of Candida species to form drugresistant biofilms is an important factor in their contribution to human disease. ${ }^{67}$

\section{Conclusion}

One in five HIV-positive patients had oropharyngeal candidiasis; a common opportunistic infection among HIVinfected individuals in Nepal. Biofilm producers (Candida albicans and non-albicans Candida) cause the majority of cases of oropharyngeal candidiasis and were more resistant towards commonly used antifungal drugs. Antifungal drug clotrimazole is highly effective against Candida isolates.

\section{Availability of Supporting Data}

All data pertaining to this study are within the manuscript.

\section{Ethical Approval and Consent to Participate}

The study obtained ethical approval from Nepal Health Research Council (NHRC Registration Number 614/ 2018). All aspects of the study were conducted according to Good Clinical Practice (GCP) and Good laboratory Practice (GLP) guidelines. Written informed consent (thumbprint or signature) was obtained from the participant. Participant information was securely stored and identified by Study Number.

\section{Acknowledgments}

We acknowledge the Sukraraj Tropical and Infectious Disease Hospital, Teku, Kathmandu for support. We thank all the team members, laboratory technicians of hospital and staff of the Central Department of Microbiology, Tribhuvan University, for their strong and generous support throughout the study period. We are grateful to all the HIV patients who cooperated to be enrolled in the study. We would like to express our gratitude to Mr. Gordon Tambellini, USA for proofreading and edits.

\section{Author Contributions}

All authors contributed to data analysis, drafting and revising the article, gave final approval of the version to be published, and agree to be accountable for all aspects of the work. All authors reviewed the final version of the manuscript and approved the final version of the manuscript.

\section{Funding}

This research was supported by the Departmental fund of Central Department of Microbiology, Tribhuvan University, Kirtipur, Kathmandu.

\section{Disclosure}

The authors declare that they have no competing interests.

\section{References}

1. UNAIDS. Global HIV \& AIDS statistics-2019 fact sheet. 2019. Available from https://www.unaids.org/en/resources/fact-sheet. Accessed February 20, 2020.

2. Pendse R, Gupta S, Yu D, Sarkar S. HIV/AIDS in the South-East Asia region: progress and challenges. J Virus Erad. 2016;2:1-6.

3. National Center for AIDS \& STD Control (NCASC),Nepal. Fact sheet 1: HIV epidemic update of Nepal. 2018. Available from http://www. ncasc.gov.np/WAD2018/FACTSHEET-2018-FINAL/Factsheet-2018final.pdf. Accessed February 20, 2020.

4. Limper AH. The changing spectrum of fungal infections in pulmonary and critical care practice: clinical approach to diagnosis. Proc Am Thorac Soc. 2010;7:163-168. doi:10.1513/pats.200906-049AL

5. Koziel H, Eichbaum Q, Kruskal BA, et al. Reduced binding and phagocytosis of Pneumocystis carinii by alveolar macrophages from persons infected with HIV-1 correlates with mannose receptor downregulation. J Clin Invest. 1998;102:1332-1344. doi:10.1172/JCI560

6. Samaranayake YH, Samaranayake LP. Candida krusei: biology, epidemiology, pathogenicity and clinical manifestations of an emerging pathogen. J Med Microbiol. 1994;41:295-310. doi:10.1099/0022261541-5-295

7. Samaranayake YH, Samaranayake LP, Wu PC, So M. The antifungal effect of lactoferrin and lysozyme on Candida krusei and Candida albicans. APMIS. 1997;105:875-883. doi:10.1111/j.1699-0463.1997. tb05097.x

8. Scully C, el-Kabir M, Samaranayake LP. Candida and oral candidosis: a review. Crit Rev Oral Biol Med. 1994;5:125-157. doi:10.1177/ 10454411940050020101 
9. Agrawal A, Singh A, Verma R, Murari A. Oral candidiasis: an overview. J Oral Maxillofac Pathol. 2014;18:S81-85. doi:10.4103/ 0973-029X.141325

10. Cameron DW, Heath-Chiozzi M, Danner S, et al. Randomised placebo-controlled trial of ritonavir in advanced HIV-1 disease. The advanced HIV disease ritonavir study group. Lancet. 1998;351:543-549. doi:10.1016/S0140-6736(97)04161-5

11. Hood S, Evans J, Bond J, Wilkins E, Denning D. The treatment of oropharyngeal candidiasis in HIV-infected patients with oral amphotericin B suspension. AIDS Patient Care STDS. 1998;12:625-627. doi:10.1089/apc.1998.12.625

12. Revankar SG, Sanche SE, Dib OP, Caceres M, Patterson TF. Effect of highly active antiretroviral therapy on recurrent oropharyngeal candidiasis in HIV-infected patients. AIDS. 1998;12:2511-2513.

13. Badiee P, Alborzi A, Davarpanah MA, Shakiba E. Distributions and antifungal susceptibility of Candida species from mucosal sites in HIV positive patients. Arch Iran Med. 2010;13:282-287.

14. Mohamed S, Al-Ahmadey ZZ. Biofilm formation and antifungal susceptibility of Candida isolates from various clinical specimens. Br Microbiol Res J. 2013;3:590-601.

15. AK P, Jain NR, Joshi R. Antibiogram of Candida species isolated from mono and multi-species oral candidal carriage using disk diffusion method. Saudi J Health Sci. 2012;1:132-138. doi:10.4103/22780521.106082

16. Melkamu MW, Gebeyehu MT, Afenigus AD, et al. Incidence of common opportunistic infections among HIV-infected children on ART at Debre Markos referral hospital, Northwest Ethiopia: a retrospective cohort study. BMC Infect Dis. 2020;20:50. doi:10.1186/s12879-020-4772-y

17. Ratnam M, Nayyar AS, Reddy DS, Ruparani B, Chalapathi KV, Azmi SM. CD4 cell counts and oral manifestations in HIV infected and AIDS patients. J Oral Maxillofac Pathol. 2018;22:282. doi:10.4103/jomfp.JOMFP_191_17

18. Kc R, Adhikari S, Bastola A, et al. Opportunistic respiratory infections in HIV patients attending sukraraj tropical and infectious diseases hospital in Kathmandu, Nepal. HIV AIDS. 2019;11:357-367. doi:10.2147/HIV.S229531

19. Suryana K, Suharsono H, Antara I. Factors associated with oral candidiasis in people living with HIV/AIDS: a case control study. HIV AIDS. 2020;12:33-39. doi:10.2147/HIV.S236304

20. Chattopadhyay A, Patton LL. Smoking as a risk factor for oral candidiasis in HIV-infected adults. $J$ Oral Pathol Med. 2013;42:302-308. doi:10.1111/jop.12019

21. Keten HS, Keten D, Ucer H, Yildirim F, Hakkoymaz H, Isik O. Prevalence of oral Candida carriage and Candida species among cigarette and maras powder users. Int J Clin Exp Med. 2015;8:9847-9854.

22. Rodrigues CF, Rodrigues ME, Henriques M. Candida sp. Infections in patients with diabetes mellitus. J Clin Med. 2019;8:76. doi:10.3390/jcm8010076

23. Bhattacharjee P. Epidemiology and antifungal susceptibility of Candida species in a tertiary care hospital, Kolkata, India. Balt J Health Phys Act. 2016;2(2):20-27. doi:10.18869/acadpub.cmm.2.2.5

24. Khadka S, Sherchand JB, Pokhrel BM, et al. Isolation, speciation and antifungal susceptibility testing of Candida isolates from various clinical specimens at a tertiary care hospital, Nepal. BMC Res Notes. 2017;10:218. doi:10.1186/s13104-017-2547-3

25. Berberi A, Noujeim Z, Aoun G. Epidemiology of oropharyngeal candidiasis in human immunodeficiency virus/acquired immune deficiency syndrome patients and CD4+ counts. J Int Oral Health 2015;7(3):20-23.

26. Ksiezopolska E, Gabaldon T. Evolutionary emergency of drug resistance in candida opportunistic pathogens. Genes. 2018;9(9):461.

27. Berkow EL, Lockhart S. Fluconazole resistance in Candida species: a current perspective. Infect Drug Resist. 2017;10:237-245. doi:10.2147/IDR.S118892
28. Sharma S, Dhungana GP, Pokhrel BM, Rijal BP. Opportunistic infections in relation to CD4 level among HIV seropositive patients from central Nepal. Nepal Med Coll J. 2010;12:1-4.

29. Dhungel BA, Dhungel KU, Easow JM, Singh YI. Opportunistic infection among HIV seropositive cases in Manipal Teaching Hospital, Pokhara, Nepal. Kathmandu Univ Med J. 2008;6:335-339. doi:10.3126/kumj.v6i3.1708

30. Pokharel S, Raut S, Adhikari B. Tackling antimicrobial resistance in low-income and middle-income countries. BMJ Glob Health. 2019;4: e002104. doi:10.1136/bmjgh-2019-002104

31. Raut S, Bajracharya K, Adhikari J, Pant SS, Adhikari B. Prevalence of methicillin resistant Staphylococcus aureus in Lumbini Medical College and Teaching Hospital, Palpa, Western Nepal. BMC Res Notes. 2017;10:187. doi:10.1186/s13104-017-2515-y

32. National Center for AIDS \& STD control. National consolidated guidelines for treating and preventing HIV in Nepal. Government of Nepal. Kathmandu, Nepal: Ministry of Health \& Population; 2014.

33. Cheesbrough M. District Laboratory Practice in Tropical Countries Part II. Cambridge: Cambridge University Press; 2006.

34. Forbes BA, Sahm DF, Weissfeld AS. Bailey and Scott's Diagnostic Microbiology. Vol. 11. St. Louis: Mosby; 2002:884-898.

35. World Health Organization (WHO). Laboratory manual for diagnosis of fungal opportunistic infection in HIV/AIDS patients. 2009 Available from https://apps.who.int/iris/handle/10665/205404. Accessed March 21, 2019.

36. Daef E, Moharram A, Eldin SS, Elsherbiny N, Mohammed M. Evaluation of chromogenic media and seminested PCR in the identification of Candida species. Braz J Microbiol. 2014;45:255-262. doi:10.1590/S1517-83822014005000040

37. Marak MB, Dhanashree B. Antifungal susceptibility and biofilm production of Candida spp. Isolated from clinical samples. Int J Microbiol. 2018;2018:7495218. doi:10.1155/2018/7495218

38. Wayne PC. Clinical and Laboratory Standards Institute (CLSI). Method for Antifungal Disk Diffusion Susceptibility Testing of Yeasts. 3rd ed. CLSI guidelines M44; 2018.

39. Khwakhali US, Denning DW. Burden of serious fungal infections in Nepal. Mycoses. 2015;58(Suppl 5):45-50. doi:10.1111/myc.12393

40. Anwar KP, Malik A, Subhan KH. Profile of candidiasis in HIV infected patients. Iran J Microbiol. 2012;4:204-209.

41. Singh A, Bairy I, Shivananda PG. Spectrum of opportunistic infections in AIDS cases. Indian J Med Sci. 2003;57:16-21.

42. Wadhwa A, Kaur R, Agarwal SK, Jain S, Bhalla P. AIDS-related opportunistic mycoses seen in a tertiary care hospital in North India. $J$ Med Microbiol. 2007;56:1101-1106. doi:10.1099/jmm.0.46893-0

43. Goulart LS, Souza WWR, Vieira CA, Lima JS, Olinda RA, Araujo C. Oral colonization by Candida species in HIV-positive patients: association and antifungal susceptibility study. Einstein. 2018;16:eAO4224.

44. Ribeiro Ribeiro AL, de Alencar Menezes TO, de Melo Alves-junior S, de Menezes SA, Marques-da-Silva SH, Rosario Vallinoto AC. Oral carriage of Candida species in HIV-infected patients during highly active antiretroviral therapy (HAART) in Belem, Brazil. Oral Surg Oral Med Oral Pathol Oral Radiol. 2015;120:29-33. doi:10.1016/j. oooo.2015.03.008

45. Khedri S, Santos ALS, Roudbary M, et al. Iranian HIV/AIDS patients with oropharyngeal candidiasis: identification, prevalence and antifungal susceptibility of Candida species. Lett Appl Microbiol. 2018;67:392-399. doi:10.1111/lam.13052

46. Paula SB, Morey AT, Santos JP, et al. Oral Candida colonization in HIV-infected patients in Londrina-PR, Brazil: antifungal susceptibility and virulence factors. $J$ Infect Dev Ctries. 2015;9:1350-1359. doi: $10.3855 /$ jidc. 6970

47. Costa CR, Cohen AJ, Fernandes OF, et al. Asymptomatic oral carriage of Candida species in HIV-infected patients in the highly active antiretroviral therapy era. Rev Inst Med Trop Sao Paulo. 2006;48:257-261. doi:10.1590/s0036-46652006000500004 
48. Kwamin F, Nartey NO, Codjoe FS, Newman MJ. Distribution of Candida species among HIV-positive patients with oropharyngeal candidiasis in Accra, Ghana. J Infect Dev Ctries. 2013;7:41-45. doi: $10.3855 /$ jidc. 2442

49. De Bernardis F, Chiani P, Ciccozzi M, et al. Elevated aspartic proteinase secretion and experimental pathogenicity of Candida albicans isolates from oral cavities of subjects infected with human immunodeficiency virus. Infect Immun. 1996;64:466-471.

50. Lattif AA, Banerjee U, Prasad R, et al. Susceptibility pattern and molecular type of species-specific Candida in oropharyngeal lesions of Indian human immunodeficiency virus-positive patients. J Clin Microbiol. 2004;42:1260-1262. doi:10.1128/JCM.42.3.1260-1262. 2004

51. Campisi G, Pizzo G, Milici ME, Mancuso S, Margiotta V. Candidal carriage in the oral cavity of human immunodeficiency virus-infected subjects. Oral Surg Oral Med Oral Pathol Oral Radiol Endod. 2002;93:281-286. doi:10.1067/moe.2002.120804

52. Urama EU, Enweani IB, Oshim IO, Okeke-Nwolisa BC, John GU. Microbiological Profile of Respiratory Tract Infections Among HIV Sero-Positive Subjects Attending Nnamdi Azikiwe University Teaching Hospital Nnewi, Nigeria. Amer J Med and Med Sci. 2018;8:37-42.

53. Ochiabuto OM, Nwankow A, Enweani B, et al. Fungal isolation in HIV patients and CD4 count. Int STD Res Rev. 2014;2(2):101-112. doi:10.9734/ISRR/2014/10408

54. Tercas AL, Marques SG, Moffa EB, et al. Antifungal drug susceptibility of Candida species isolated from HIV-positive patients recruited at a public hospital in Sao Luis, Maranhao, Brazil. Front Microbiol. 2017;8:298. doi:10.3389/fmicb.2017.00298

55. Leigh JE, Barousse M, Swoboda RK, et al. Candida-specific systemic cell-mediated immune reactivities in human immunodeficiency virus-positive persons with mucosal candidiasis. $J$ Infect Dis. 2001;183:277-285. doi:10.1086/317944

56. Negi M, Sepolia N, Panwar SS, Kumar M, Singla J, Aggarwal RK. Prevalence of oral parameters in smokeless tobacco-associated precancer. J Family Med Prim Care. 2019;8:3956-3961. doi:10.4103/ jfmpc.jfmpc_667_19
57. Darwazeh AM, Al-Dwairi ZN, Al-Zwairi AA. The relationship between tobacco smoking and oral colonization with Candida species. J Contemp Dent Pract. 2010;11:17-24. doi:10.5005/jcdp-11-3-17

58. G T, Preuss O, Aniko-Włodarczyk M, et al. The effect of nicotine on oral health. Balt J Health Phys Act. 2018;10:7-13.

59. Subramanya SH, Baral BP, Sharan NK, et al. Antifungal susceptibility and phenotypic virulence markers of Candida species isolated from Nepal. BMC Res Notes. 2017;10:543. doi:10.1186/s13104017-2852-x

60. Maurya V, Srivastava A, Mishra J, et al. Oropharyngeal candidiasis and Candida colonization in HIV positive patients in northern India. J Infect Dev Ctries. 2013;7:608-613. doi:10.3855/jidc.2801

61. Enwuru CA, Ogunledun A, Idika N, et al. Fluconazole resistant opportunistic oro-pharyngeal Candida and non-candida yeast-like isolates from HIV infected patients attending ARV clinics in Lagos, Nigeria. Afr Health Sci. 2008;8:142-148.

62. Deorukhkar SC, Saini S, Mathew S. Non-albicans Candida infection: an emerging threat. Interdiscip Perspect Infect Dis. 2014; 2014:615958.

63. Cavalheiro M, Teixeira MC. Candida biofilms: threats, challenges, and promising strategies. Front Med. 2018;5:28. doi:10.3389/ fmed.2018.00028

64. Lewis K. Riddle of biofilm resistance. Antimicrob Agents Chemother. 2001;45:999-1007. doi:10.1128/AAC.45.4.999-1007.2001

65. Li YY, Chen WY, Li X, et al. Asymptomatic oral yeast carriage and antifungal susceptibility profile of HIV-infected patients in Kunming, Yunnan Province of China. BMC Infect Dis. 2013;13:46. doi:10.1186/ 1471-2334-13-46

66. Whaley SG, Berkow EL, Rybak JM, Nishimoto AT, Barker KS, Rogers PD. Azole antifungal resistance in Candida albicans and emerging non-albicans Candida species. Front Microbiol. 2016;7:2173.

67. Rodrigues CF, Silva S, Henriques M. Candida glabrata: a review of its features and resistance. Eur $J$ Clin Microbiol Infect Dis. 2014;33:673-688. doi:10.1007/s10096-013-2009-3
HIV/AIDS - Research and Palliative Care

\section{Publish your work in this journal}

HIV/AIDS - Research and Palliative Care is an international, peerreviewed open-access journal focusing on advances in research in HIV, its clinical progression and management options including antiviral treatment, palliative care and public healthcare policies to control viral spread. The manuscript management system is completely online and includes a very quick and fair peer-review system, which is all easy to use. Visit http://www.dovepress.com/testimonials.php to read real quotes from published authors. 